\title{
Determinants of unplanned pregnancy among women: A case of Awach Health Centre IV in Gulu district.
}

\author{
Norman Okae ${ }^{a, 1}$, Jane Kasozi Namaggaa, Grace Nambooze \\ a Department of Nursing, Mbarara University of Science and Technology
}

Abstract

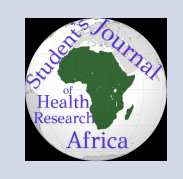

Background:

Planning of pregnancy is a pertinent public health practice that every woman should embrace at her reproductive age. It is considered a major necessity in adopting a healthier lifestyle before pregnancy that leads to positive maternal-child health outcomes. On the contrary, unplanned pregnancy is ranked among the major public health problems that predispose women to huge mortality and morbidity mainly through criminal/unsafe abortion coupled with poor post-abortion care.

Methodology:

We used descriptive designs, employing qualitative approaches. We purposely selected 10 participants who lived within Aswa County, to participate in the study. Data were collected using an in-depth interview. Interpretive content analysis was used to generate categories and themes.

Results:

The study generated four themes namely: individual determinants, family determinants, community determinants, and health facility determinants of an unplanned pregnancy.

Conclusion and Recommendations :

This study has contributed substantially in revealing determinants of an unplanned pregnancy. In Awach Health Centre IV, the determinants of unplanned pregnancy are sexual desires, prostitution, school-going status, income level, number of sexual partners, amenorrhoea, marital status, contraceptives usage, religion, domestic violence, family planning discussion with husband. Others are; breastfeeding status during conception, the gender of existing children, recurrent obstetrical complications, distance from husband, rape, peer pressure, denial of pregnancy by men, type of settlement, contraceptive failure, and lack of sensitization.

There is a need for a multi-level approach to address determinants of unplanned pregnancy ranging from individuals, families, communities, and health facilities approach. Improvement in the economic status of women, and implementing programs that encourage education of women/girl child could reduce unplanned pregnancy.

\section{Background:}

Planning of pregnancy is a pertinent public health practice that every woman should embrace at her reproductive age (Mann, 2018). Consequently, this helps a woman to conceive consciously by her choice. It is considered a major pre-requisite in adopting a healthier lifestyle before pregnancy that leads to positive maternal health outcomes (Bukenya et al., 2019). On the contrary, unplanned pregnancy is ranked among the major public health problems that predispose women to huge mortality and morbidity mainly through criminal/unsafe abortion coupled with poor post-abortion care (Mili et al., 2015, Habib et al., 2017, Faiza et al., 2016). 
Globally the determinants of unplanned pregnancy are linked with adverse health social consequences (Singh et al., 2010). This may be due to its adverse effects on maternal and neonatal health coupled with social and economic outcomes, which increase the risks of mortality (Habib et al., 2017). Unplanned conceptions can be caused by failed contraception, not using family planning methods, incidental timely intercourse, or sometimes due to rape. This may result in health problems for women, children, and their families (Eleni et al., 2018, Yitayal and Azeb, 2019, Ramesh et al., 2009). The possible consequences of unplanned pregnancy, range from unsafe abortion, late antenatal care (ANC), poor maternal mental health, eclampsia, and pre-eclampsia. Others include postpartum hemorrhage, reduced mother-child bonding, low birth weight for babies, and increased maternal morbidity and mortality (Sebestian et al., 2014).

Despite the above-mentioned consequences, the determinants of unplanned pregnancy are not well documented in the study area. Therefore, this study seeks to identify the determinants of unplanned pregnancy among women aged 18 to 49 years attending Awach $\mathrm{H} / \mathrm{C}$ IV in the Gulu district

Unplanned pregnancy (UP) occurs when no children or no more children are desired at conception time (Ramesh et al., 2009, Emire et al., 2012). Due to several social or economic reasons, most women or partners desire to plan on when to conceive and how to space their children to prevent unplanned pregnancy (Mariza et al., 2016).

Some studies have reported that out of 210 million pregnancies that occur worldwide, 38\% are unplanned (80 million pregnancies annually), $22 \%(17,600,000)$ of which ends up in abortion (Lawrence et al., 2013). Surprisingly, a vast majority of these abortions are performed using unsafe techniques, placing a huge burden on health systems, especially in developing countries (Lawrence et al., 2013).

Unplanned pregnancy is common among different categories of women such as; single women, women with multiple partners, low educational level, low income, and failure to use family planning methods. Others include; multiparous mothers, young women, unemployed, and women who do not visit health care facilities (Yitayal and Azeb, 2019).
Literature review revealed that unplanned pregnancies (UP) in developing countries still occur at a wide range of $14 \%$ to $62 \%$, the highest being in sub-Saharan African (SSA) countries (Faiza et al., 2016; Victoria et al., 2018). An estimated 86 unplanned conceptions occur in every 1000 pregnancies among women of reproductive age (Faiza et al., 2016). A multi-country analysis of UP was done in SSA by demographic and health survey (DHS). The results were ranging from $10.8 \%$ in Nigeria up to $54.5 \%$

in Namibia with a mean prevalence of $29 \%$ for all the 29 countries across SSA (Edward et al., 2019). This indicates that there is a high need to consider interventions like health education, counseling, building life skills, and comprehensive sex education to improve contraceptive access and utilization. Similarly, a study done in southwestern Nigeria indicated that up to $35.9 \%$ of women had pregnancies that were unplanned, with $33.5 \%$ cases of induced abortion (Adelaja, 2015). This might have put a health risk to these women unknowingly. In Kenya, a study done in Nairobi found that 24\% of women had UP, with a considerable variation between slum dwellers (21\%) as compared to $27 \%$ non-slum settlement (Lawrence et al., 2013). This prevalence was associated significantly with marital status, employment status, ethnicity, age, and type of settlement.

In Uganda, it is reported that more than 4 in 10 births (32\%) are unplanned (Rubina, 2013). On average, women have 6.2 children but only intend to have 4.5 children in their lifetime (UDHS, 2011). This could be because these women fail to use contraceptives even if they do not want to become pregnant. Women in the Eastern and Northern regions have outrageous proportions of unplanned births (54\%) compared to other regions (Rubina, 2013). This might be due to 20 years of civil war in the Northern region, which displaced people in camps leading to poverty. Similarly, the eastern region is as poor as the northern region resulting in low socio-economic status and underutilization of contraceptive methods leading to an unplanned pregnancy. Low Socio-Economic Status (SES) could result in UP due to inability to afford money for transport to seek contraceptives, long-distance to the facility.

A study was done in Gulu district in 2019, and the prevalence of unplanned pregnancy among female sex workers was estimated as $44 \%$ (Bukenya 
et al., 2019). This is a high prevalence in one district out of 134 districts in Uganda. There are no documented determinants of unplanned pregnancy among women in this study area.

\section{Methodology:}

\section{Study area}

The study was carried out in Awach H/C IV, Gulu District. Awach H/C IV is located in Awach Sub County, Aswa County headquarter. The facility center was established in 1931 (Personal communication, 2019b). The health facility is situated in northern Uganda about $371 \mathrm{~km}$ by road from

Uganda's capital city, Kampala, and $31 \mathrm{~km}$ from Gulu municipality (Calculator, 2015). It serves as a major referral site for all the twenty (20) health facilities in Aswa Health sub-district covering the sub-counties of Awach, Paicho, Unyama, Bungatira, Patiko, and Palaro. The health facility has a bed capacity of 28 both in maternity and general wards with a catchment population of twentyone thousand nine hundred nineteen $(21,919)$ people (Awach Health Centre IV, FY2018/2019). The health center has various clinics such as outpatient, post-natal, ART clinic, maternity, outpatient departments, antenatal, maternity, general ward among others. The study was conducted in an antenatal clinic. This area was chosen because it has a very large catchment population covering all the five sub-counties outside Gulu municipality where women come from peri-urban, semi-urban and others from typical village locations. This, therefore, captured women with a wide range of backgrounds and lifestyles that provided a wide yield of information suitable for this study. It was also convenient to the researcher due to easy accessibility and adequate knowledge about the community's socioeconomic and cultural characteristics.

\section{Design of the study and rationale}

This study used descriptive design, employing qualitative approaches. Qualitative research handles non-numerical information and aims to answer questions concerned with what something is like, what people think or feel about an unplanned pregnancy. Qualitative inquiry explores peoples' experiences regarding some phenomenon and how they interpret those experiences (Kate, 2011).

\section{Study population}

The study population included all women aged 18 to 49 years from within Aswa County attending ANC.

\section{Sampling method}

The investigator employed purposeful sampling to select participants for this study. This enabled the investigator to identify information-rich participants (Patton, 2002). Similarly (Taherdoost, 2016) also recommends this method as the best for selecting participants who would give high yielding information.

\section{Sampling size determination}

Literature reveals that sample size is not predetermined in qualitative research. Information power indicates that the more information the sample holds relevant for the actual study, the lower the number of participants required. However, a sample of 10-20 was considered. This was determined by saturation when no new information was being generated from participants (Malterud et al., 2016)

\section{Inclusion and exclusion criteria Inclusion criteria}

Pregnant women aged 18 to 49 attending ANC services that consented to participate in the study on the days of data collection were eligible. This

wide range of age provided rich information (Althubahaiti, 2016)

\section{Exclusion criteria}

Women who needed immediate medical services, women outside Aswa County were not allowed to participate in the study.

\section{Pilot study}

This is a micro-study performed before a researcher carrying out a large-scale study to help them decide how best a large-scale research can be performed (Crossman, 2019). This was carried out at Cwero Health Centre III, on five women aged 18 49 and their findings were not included in the study. This was excluded because; it was only aimed to examine the feasibility of the approach intended to be used in the large-scale research. This was carried out before the main study to ensure that the data collection tool was appropriate, understood, and was gathering the information addressing the research question. Whatever question was not clear was modified before the actual study. Conducting the pilot study also guided the researcher on the questioning techniques before the study.

\section{Data collection tools}


A pre-designed tested semi-structured interview guide consisting of two parts: participant's demographic characteristics and interview questions was used. The tool was chosen because a semistructured interview offers ample time for the interviewee to express herself and may ask questions (Bennett et al., 2018). This was guided by a literature review and conceptual framework that was designed in English by the researcher and translated into the local Luo language with the support of a linguist. The interview guide helped me to gather information on determinants of UP among women attending services in the study area.

\section{Data collection procedure}

After getting permission from the health facility, informed consent was obtained from Potential women attending ANC who met the inclusion criteria. Participants were interviewed using in-depth semi-structured interviews face to face. Permission was sought to use audio recordings of the interview. Participants were also told that the interview would last $30-45$ minutes. The interviewer asked a grand tour question; "in your own view, what do you think are the causes of unplanned pregnancy among women". Probing questions were asked for clarity in order to give an appropriate response in relation to the research topic (Patton, 2002) At the end of the interview participants were thanked.

\section{Rigors of the study}

This was achieved by ensuring trustworthiness, employing various terms such as credibility, transferability, confirmability, and dependability (Elo et al., 2014, Polit and Beck, 2012).

\section{Credibility}

This refers to how participants view and interpret the data and how a researcher observes confidence and the truth of the study found. (Cope, 2014, Polit and Beck, 2012). This was achieved by pre-testing the interview guide, translating the guide into the local language so that the participants could easily understand, and then back-translated to English to ensure credibility was not lost. olonged engagement of 30-45 minutes elicited credible information. The use of the purposive sampling method also promoted the credibility of the study.

\section{Confirmability}

This means the capability of the researcher to show that the data collected represents exactly the response by participants and not the business or point of view of a researcher (Cope, 2014, Polit and Beck, 2012). This was considered by clearly defining the characteristics of the participants, the study area, and methods used for data collection. The responses were recorded and Codes were used to ensure that data collected were not mixed in any way.

\section{Dependability}

Dependability refers to how constant a data is, given the same conditions where different researchers could be able to find the same information as the researcher (Cope, 2014, Polit and Beck, 2012). This was ensured by using a semi-structured interview guide to collect information that was related to the purpose of the study. This allowed participants to express themselves and gave their views.

\section{Transferability}

This is how the researcher demonstrates how the research study findings apply to other contexts that have similar populations and states (Polit and Beck, 2012). This was achieved by clearly defining the characteristics of the participants, the study area and methods used for collecting data, how it reached redundancy, and the finding as well. The reader will make their own judgment if the findings apply to their setting.

\section{Data analysis}

Data were analyzed using interpretive content analysis. This was deemed more desirable for this study as it preserves as much as possible, the deep meaning of qualitative data. Furthermore, enabled the interpretation of all transcribed interviews, documents, and notes of observations and relating each to the whole to gain a holistic picture of the phenomenon (Elbardan and Othman 2017). Data were transcribed verbatim; the researcher read line-by-line and generated similar categories of paragraphs, phrases, and statements in the participant responses.

\section{Ethical consideration}

The proposal was submitted to the Faculty Research Committee -MUST for ethical approval. The Head of Department gave an introductory letter to the researcher. This letter was presented to the in-charge Awach H/C IV who granted permission to allow the researcher to collect data from the Health Centre.

Informed consent was obtained from the respondents before the interview. They were reassured in an advance prior interview that participation in 
the study was voluntary, the information that was gathered from them would be kept confidential, and no name was used. Above all, they had to feel free to opt-out before or during the interview in case of discomfort without any penalty. They were however encouraged that; their participation in the study was of great important

\section{Study limitations}

Time-consuming process since I used personal experience and knowledge to influence observations and conclusions.

Risk and fear for infection with Covid-19 both to the respondents and data collector. Proper counseling, use of facemasks, keeping distance, hand sanitizing, and handwashing, mitigated this.

Since the study was based in the health center, there was the likelihood that true determinants of unplanned pregnancy in the community could not be revealed.

\section{Dissemination of results}

The research dissertation copies will be submitted to the main library, nursing department Mbarara University of Science and technology, Awach Health Center IV, each of them receiving one copy. The study findings will be presented in conferences and published in reputable journals.

\section{RESULTS}

\section{Demographic characteristics of participants}

The study involved 10 participants whose ages ranged from 18 to 49 years. Of the 10 participants, the median age was 27 years. $40 \%$ were aged $18-25$ years and $40 \%$ were aged $26-35$ years and only $20 \%$ were aged 36 years and above. Most of the participants were Catholics (50\%), followed by Protestants (30\%) and 20\% were Pentecostal Assembly of God. A great number (70\%) of the participant ended in primary, $20 \%$ of the participants reached secondary, and only (10\%) achieved tertiary education as a Grade III teacher. A vast majority, (70\%) of the participants were peasant farmers, with only (20\%) being occupied as business ladies and only $10 \%$ as a primary school teacher $A$ half of the participants were married and the race was either unmarried or separated with their husbands. A great number (60\%); of the participants had less than three children and the rest (40\%) had three or more children.

\subsubsection{Table 2: Demographic characteristics of participants: \\ 4.2 Determinants of unplanned pregnancy:}

Four themes emerged from the study findings as the determinants of unplanned pregnancy among pregnant women attending ANC namely: individual determinants; family determinants; community determinants and health facility determinants as shown in the table below:

\subsubsection{Table 3: Themes and category that emerged from the study}

\section{Theme 1: Individual determinants}

The theme individual determinants emerged from 10 categories namely; Too much desire for sex/sex only to fulfill desires, Prostitution, School going girls, Low income/poverty, Multiple concurrent sexual partners, Single mothers/divorce, Taking long without periods.

\section{Category 1: Too much desire for sex/sex only} to fulfill needs

Too much desire for sex determines unplanned pregnancy. The participants reported that having too many desires for sex led to unexpected sex with a man leading to an unplanned pregnancy.

“...you find that a woman just goes to fulfill her bodily sexual desire with a man, but pregnancy comes abruptly. She thinks that when she delivers that baby; taking responsibility for feeding, school fees will be a burden to her alone; so, abortion is the best option. $\mathrm{Hmmm} \mathrm{hmmm....} \mathrm{men} \mathrm{just} \mathrm{come} \mathrm{to} \mathrm{fulfill} \mathrm{their} \mathrm{needs}$ and run away ..." (p 2, p6).

\section{Category 2: Prostitution}

Prostitution determines unplanned pregnancy. The participants reported that prostitutes consider pregnancy and childbearing as hindering factors and therefore unplanned since their customers do not transact with pregnant or breastfeeding women.

“....... Prostitutes (Uganda Kob- meaning they eat peoples' garden) does not want to get pregnant or have a child because it disrupts their market, spoils their smartness, distorts their figures and time-wasting to care for a child" .... (p6).

\section{Category 3: School going girls/pre-marital} sex

Girls who are still at school can have unplanned pregnancies. Students still want to continue with their studies to pave a brighter future. 
Table 1. Demographic characteristics of participants.

\begin{tabular}{lll}
\hline Variables & Frequency (N=10) & Percentage (\%) \\
Age & 4 & 40 \\
$18-35$ years & 4 & 40 \\
$26-35$ & 2 & 20 \\
36 and above & & \\
Religion & 2 & 20 \\
Pentecostal Assembly of God (PAG) & 5 & 50 \\
Catholics & 3 & 30 \\
Protestant & & \\
Education & 7 & 70 \\
Primary & 2 & 20 \\
Secondary & 1 & 10 \\
Tertiary & & \\
Occupation & 7 & 70 \\
Peasant farmer & 2 & 20 \\
Business & 1 & 10 \\
Civil servant & & \\
Marital status & 5 & 50 \\
Married and staying with husband & 5 & 50 \\
Single/divorced & 5 & 60 \\
Number of children & & 40 \\
Less than 3 children & 6 & \\
3 or more children & 4 & \\
\hline
\end{tabular}

Table 2. Themes and category that emerged from the study

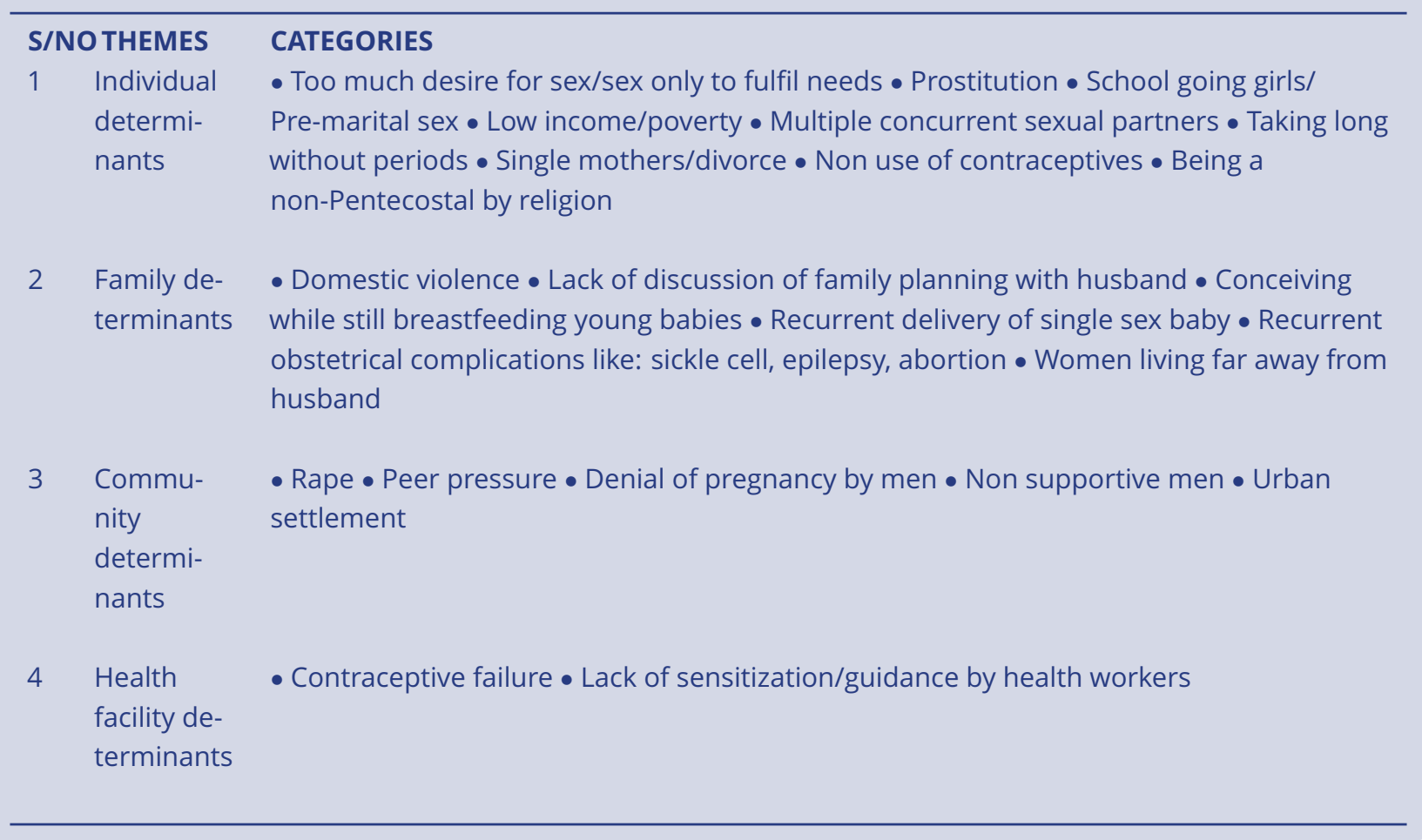


“... some girls still want to continue with studies and others fear harsh reaction by parents when they get pregnant so they consider pregnancy as unplanned...... (p3, p5).

\section{Category 4: Low income/poverty}

Low income can determine unplanned pregnancy among women. Participants reported that poor women had a high risk of an unplanned pregnancy.

“... a poor woman may love a man expecting to get financial support in turn from him, that may end into an unplanned pregnancy, but you find that a man may not have the intension of impregnating you, but to just fulfill his desires. A man loving you just to fulfill his desires may say: "I am too old to care for a newborn baby"' ... (p4).

".... you find that some women here don't have ability/money to take care of the pregnancy so when they get pregnant, they consider the pregnancy unwanted/unplanned" ... (p6, p8).

"women with low income will wait until free family planning service is brought to the nearby place, example when Maristopes comes: but a woman with high income can seek family planning at any place of choice" ... (p8).

Category 5: Multiple concurrent sexual partners

Multiple sexual partners lead to an unplanned pregnancy. Participants reported that women who have many sexual partners have a high risk of an unplanned pregnancy.

"...you find that some girls have many sexual partners when they get pregnant usually fails to identify the exact man responsible for the pregnancy; even if you go to them they just dodge you. Worse of all suppose my parents ask me to tell the man responsible for the pregnancy, even I don't know...... they take this pregnancy as unplanned and the best option is to abort" ...... (p4).

\section{Category 6: Single mothers/divorce}

Being a single/ divorced woman leads to an unplanned pregnancy. Participants reported that women who are single or have divorced have a high risk of UP compared to married women.

".... Hee hee.... you find a single woman is having 2 or more men... today you have this one, the next day another one! Ultimately in a day they end up being used by 8 men....." (p2, p8).

"...you find that single ladies have freedom (like winter goats), they have many men lovers coupled with unplanned sex that leads to an unplanned pregnancy.
But the married discuss family planning and sex plan with the husband" ..... (p 6, p 5, p 3).

\section{Category 7: Taking long without periods}

Taking long without a normal menstruation period can lead to an unplanned pregnancy. Participants reported a prolonged absence of menstruation as a cause of unplanned pregnancy.

".. You find you have been using family planning such as injection for three months and you do not see periods after stopping injection and you have sex with a man thinking you are safe and you just realize the stomach is becoming big. This happened to me with my second pregnancy which I didn't expect" ............. (p 10)

\section{Category 8: Non- use of contraceptives}

Nonuse of contraceptives determines unplanned pregnancy in this study. A participant reported not using family planning by a woman could lead to abrupt pregnancy as noted in the excerpts.

“... You can get abrupt pregnancy sometimes when you do not protect yourself using family planning methods like condoms.... You go for live sex just recklessly" (p7)

\section{Category 9: Being a non-Pentecostal (PAG) by} religion:

Being a non-Pentecostal by faith determines unplanned pregnancy. Participants reported that religious denominations other than Pentecostal Assembly of God (PAG) have a higher chance of unplanned pregnancy as narrated in the following excerpts:

"PAG adheres strictly to bible doctrine pertaining -one woman one man......(quoted) the Bible says multiply and fill the world but with only one man......... woman found practicing immorality is nicknamed 'Malaya' meaning a prostitute" ...... (p6).

\section{Theme 2: Family determinants}

The theme emerged from six categories:

\section{Category 1: Domestic violence}

Domestic violence is a determinant of an unplanned pregnancy. Participants reported that physical, sexual violence could lead to an unplanned pregnancy.

“....... sometimes a man may need a new baby and just force you into sex when you are not ready for sex leading to unplanned pregnancy" .... (p1)

"......a man may be suspicious that the pregnancy is not his......this leads to fighting, abuse and lack of support from the man and you just feel like removing the fetus" .... (p2, p9). 


\section{Category 2: Lack of discussion of family plan- ning with husband}

Lack of discussion of family planning with the husband can lead to an unplanned pregnancy. A participant reported failure to agree on family planning.

"......you find that a man is putting you on the pressure to get another baby when you are not yet prepared.... (Breathed deeply)... he can even throw away my pill plan leading to unplanned pregnancy.... (p5, p2)

\section{Category 3: Low income/poverty}

Low income can lead to an unplanned pregnancy. Participants reported low income to access family planning, keep the pregnancy, and take responsibility after delivery evidenced in the illuminative quote below;

“....... you find that you don't have a reliable source of money to take care of the pregnancy or baby... even my parents may be too poor to assist me; sometimes you think of removing the fetus...(p4).

Category 4: Conceiving while still breastfeeding young babies

Conceiving while still breastfeeding a young baby can lead to unplanned or unwanted pregnancy. A participant reported that getting pregnant when the baby is still very young could make a woman feel that the pregnancy is not planned for as evidenced in the following excerpts:

"... you find that I have a very young baby who is still breastfeeding; when you get abrupt pregnancy malnutrition will affect him or her and there is need to give him enough nurture.... any pregnancy that comes while breastfeeding is considered unplanned" .... (p9)

\section{Category 5: Recurrent delivery of single-sex babies}

Delivery of single-sex babies results in an unwanted pregnancy. A participant from Latwong village reported that men want baby boy when a woman recurrently produces baby girls it brings misunderstanding.

"....... most times when a woman repeatedly delivers baby girls...hey... held her cheek; the man will not be happy... so I rather think of removing the baby and dump away" ......... (p10).

Category 6: Recurrent obstetrical complications/abnormalities like sickle cell, epilepsy, abortion

The participant reported recurrent occurrence of a congenital abnormality or obstetrical complica- tion as a determinant of an unplanned pregnancy. Participant $p 10$ specifically testified on herself producing 4 babies with sickle cell disease.

"... you find that...(paused)... like me who has been producing such children with a sickle cell which is so disabling and all the time, you find we are admitted in the ward... I developed a fear that the next pregnancy will be again a Sickler....so I rather remove the pregnancy"... (p10)

Category 7: Women living far away from husband

Women who live far from their husbands determine unplanned pregnancies. Participants reported that many women whose husbands had stayed very far away for a longer period got involved in extramarital affairs resulting in unplanned pregnancy as noted in the excerpts;

"....... there is a woman whose husband had gone to work in Apaa river bank; she got pregnant with another man, tried to use the local herbs to induce abortion but attempts failed...... until the pregnancy went to term, delivered a normal baby. The man came back and found another infant that caused chaos ending up into divorce, even up to now the woman is at her father's home" ... (p1)

".... the man may come back abruptly without informing you when you are on danger period leading to unplanned pregnancy" ...p3)

"......you find that these women may fail to control their sexual desires for so long; for example, those whose husbands are in Somalia... they get pain killers from other men leading to unplanned pregnancy" .... (p4, p5, p6)

\section{Theme 3: community determinants \\ Category 1: Rape}

Rape can lead to an unplanned pregnancy. Participants reported being forced for sex when you don't want as evidenced by the excerpt below:

".... sometimes you can be forced to have sex when you don't even have desires for it.... smile.... even the husband can just force you so that you accept and you end up getting unplanned pregnancy... ( $55, \mathrm{p} 7$, p8).

\section{Category 2: Peer pressure}

Influence from friends can cause unplanned pregnancy. A participant reported peer pressure as evidenced by the illuminative quote below

“... you find maybe you have your friend telling you......you be with this man... you be with this boy hey... he has money; he has a car.... a very good man and for you, you will be asking... what if I get 
pregnant? And you continue and you find yourself pregnant... (p8).

\section{Category 3: Denial/ rejection of pregnancy by} men

Denial or rejection of pregnancy is another determinant of unplanned or unwanted pregnancy. Participants reported that some men could impregnate a woman and deny being responsible for the pregnancy as quoted in the following excerpts

".......you find that when you go to the hospital for antennal care, the doctor will ask, where is your husband? But you find you have no man to escort you, even health workers may not provide to you the expected services" .... (p3).

“...... what makes a woman considers a pregnancy unplanned/unwanted because a man may only come to fulfill his sexual needs and goes away leaving you with a burden of responsibility like paying school fees; so, a woman is left with ideas of removing the fetus" ... (p3, p6).

\section{Category 4: Non-supportive men}

Men who do not support their women cause a pregnancy to be unwanted or unplanned. Participants reported that men who do not support their women cause a woman to consider the pregnancy as unplanned as explain in the following excerpts;

“... say; like am now at our fathers' home, but I just have a lover to help me fulfill my needs, but if by bad luck I get pregnant that pregnancy is unplanned... and when I carry such pregnancy....... the man can neglect me without helping me to take care of the pregnancy and the baby. So the only option is to induce abortion so that I don't suffer the consequences of paying school fees, feeding and hospital bills" ... (p5, p6).

\section{Category 5: Urban settlement}

Being a woman living in the town/peri-urban area causes unplanned pregnancy. Participants reported an increased risk of unplanned pregnancy among women living within or near Awach town council as noted in the following excerpts:

"...... hmmm; in towns like Awach; you find at night, you find all types of people Lottering... the young ones; the middle age, the old ones... available are many drinking joints, video halls. Men also see women from there and start luring them for casual sex leading to an unplanned pregnancy. But in the villages like Oroko... Akor ... where girls stay together with parents without easy access to men, unplanned pregnancy is low" .... (p7, p8).
“... you find that women within/near center or town are ever dressed smartly to attract men... they even have ample time to meet men.... but rural women are ever busy with garden works. So, no time to get other men, except the husband in the house" ... (p10)

"... you find town women bleach their skin.... keep their smartness at a high level to attract the attention of men, even men look for them causing unplanned pregnancy" ...... (p9)

\section{Theme 4: Health facility determinants}

\section{Category 1: Contraceptive failure}

Failure of contraceptives to work can lead to an unplanned pregnancy. A participant reported that family planning could fail to work leading to unplanned pregnancy as narrated in the excerpts;

“.... even it happened to me! (With a sad facial expression). I went and they injected me with an injecta plan; when I was even menstruating on my second day... but after two months, surprisingly I realized I was pregnant. When I went back to the health center; they asked for my card, I gave them... they reassured me... the drug could have expired" ... (p5, p8).

\section{Category 2: Lack of sensitization/guidance} by health workers

Lack of guidance by health workers can determine unplanned pregnancy. A participant reported a lack of sensitization by health workers about unwanted pregnancy.

“......they don't go to the community to sensitize people about pregnancy planning and prevention of unplanned pregnancy" .... (p8).

\section{Summary of Chapter Four}

The chapter has discussed the determinants of unplanned pregnancy among pregnant women aged 18 to 49 years attending services at Awach H/C IV. The participants described determinants of an unplanned pregnancy as being individual, family, community, health facility determinants. The next chapter is chapter five, the discussion of results.

\section{Discussion}

\section{Demographic characteristics}

The median age was 27 years. This was an average reproductive age that falls within the target population. However, the finding was contradictory to finding by Jenny et al. (2019), Mariza et al., (2016), and Lawrence et al., (2013) who found unplanned pregnancy more common among teenagers and first-time mothers less than 20 years who were 
likely to have not used family planning. However, the result could have been affected by the target population, which excluded teenagers less than 18 years. The study was entirely dominated by Christians, the majority were specifically Catholics, and none of them was a Muslim. This finding concurs with the finding by Edward et al., (2019) that found unplanned pregnancy relatively common among Christians than Muslims. However, this could be because the study area has very little Muslim population and none of them attended the clinic during the data collection period. More so, Catholics preach against family planning with a bible quote; 'multiply and fill the world 'which is contrary to the health benefits. Most of the participants ended in the primary level of education. This means that majority of women in Awach lacks basic knowledge acquired from secondary schools, on reproductive health and preventive strategies of an unplanned pregnancy. This concurs with findings by (Yibeltal et al., (2014), Reza et al., (2018), Yitayal and Azeb, (2019) who found that unplanned pregnancy was greatly experienced by mothers with primary education and less experienced by those with secondary or tertiary education. However, it contradicts the finding that education exhibited no meaningful contribution to an unplanned pregnancy (Lawrence et al., 2013, Reza et al., 2018). A great number of participants were peasant farmers. Being peasant farmers translates to low income and this is associated with difficulty to access family planning services from a health facility. This is in line with the finding in Iran; that got the poor status of women as a determinant of unplanned pregnancy (Reza et al., 2018). The last characteristic was the number of children. The majority of participants had $<3$ children. This is because they have not yet felt the burden of child-caring and responsibility. Therefore, they loosely consider family planning as important. This is controversial to a study that found mothers with 3 or more deliveries being 14 times at risk to have unplanned conception (Mariza et al., 2016). On the other hand, a participant concurred with Mariza et al., (2016) that, women with many children have a higher risk because they fear shame since their children are already old. More so, they fear being stigmatized as competing with their daughters and daughter in-laws for pregnancy. This means elderly women consider any pregnancy that occurs unwanted.

Determinants of unplanned pregnancy

\section{Individual determinants of unplanned preg- nancy:}

The participant reported too much desire for sex/sex only to fulfill needs as a determinant of unplanned pregnancy in this study. This finding is congruent to the finding by Eleni et al., (2018, Yitayal and Azeb, (2019) who found women with incidental timely intercourse, high sexual desires, and therefore multiple partners had a high prevalence of unplanned pregnancy. Participants reported that women with multiple partners even fail to identify the real man responsible for the pregnancy.

The participant reported prostitution as a determinant of unplanned pregnancy in this study. This study particularly unveiled that; prostitutes consider any pregnancy unplanned since it acts as a hindrance to their business- denying them customers. This finding relates to a study done

among Gulu female sex workers; that found criminalized work environment as a great barrier to HIV testing and reproductive health services utilization leading to unplanned conception (Margret et al., 2015).

School-going girls/ Pre-marital sex is another determinant of an unplanned pregnancy. Participants reported that this category still wants to continue with school and more so, fear harsh reactions from their parents when they get pregnant. This is coherent with a related study that revealed age less than 20 years who are still school going or not married to have been commonly faced with UP (Jenny et al., 2019, Mariza et al., 2016, Lawrence et al., 2013).

\section{Low income/poverty determines unplanned pregnancy.}

Participants reported that a poor woman might love a man expecting to get financial support in turn from him. However, you find that a man may not have the intention of impregnating the woman, but just to fulfill his desires. This might mean that these women feel inferior to negotiate safe sex, hence exposing them to an unplanned pregnancy. This corresponds to findings by Reza et al., (2018) in a study done in Iran; they got the poor status of women as a determinant of an unplanned pregnancy. Their study revealed that socioeconomic status (SES) constituted $27 \%$ of unwanted pregnancies.

Multiple concurrent sexual partners where a woman may fail to identify the man who impregnated her leads to unwanted pregnancy in this study. The woman with many men lovers will not 
manage to balance all of them and dodge dangerous days as expected when the woman has only one partner. This is in agreement with the finding by Yitayal and Azeb, (2019) who mentioned multiple partners as a determinant of UP.

Being a single/ divorced mother determines unplanned pregnancy in this study. Single women have many men, lovers, with high chances of unplanned sex leading to UP. This reaffirms finding from Sebastian et al., (2014), Eleni et al., (2014), Mariza et al., (2016), Lawrence et al., (2013) who found marital status of women as a determinant, in which married women have less risk of having unplanned pregnancy in comparison to single mothers.

Taking long without periods caused UP in this study. Using family planning such as injection for three months and you do not see periods after stopping injection and having sex with a man has led to an unplanned pregnancy. This is a unique finding in this study area and does not correspond to any found elsewhere.

Non-use of contraceptives is a cause of unplanned pregnancy in this study. A woman may get an unexpected conception when she stays without using any family planning method but recklessly has sexual intercourse with a man. This finding is not surprising since Catholics who preach against family planning dominated the study population.

The current study result matched the finding by Aparna et al., (2017) in a study among Ugandan University students who were found not to have used any family planning method in their last sexual meeting.

Being a non-Pentecostal by religion is another determinant of unplanned pregnancy in this study. UP was common among Christians and non-among Muslim. This finding is not conclusive because the area has very few women practicing Islam faith and none of them attended ANC during interview time. The study revealed that UP was rampant among Catholics and was less common among PAG. This reaffirms findings in a study conducted in Sub-Saharan Africa that found religion to have had a relatively significant influence on pregnancy intentions. Christian women recorded $36.5 \%$ of unplanned pregnancies whereas, among Muslim women, the prevalence was only $16.9 \%$ (Edward et al., 2019).

Family determinants of unplanned pregnancy
Domestic violence was a determinant of UP in the current study. The participant reported that a man may just force her to have sex with her when she is not willingly leading to an unplanned pregnancy. On the other hand; a man may be suspicious that the pregnancy is not his; leading to many insults, abuse, and lack of support; ultimately, the pregnancy becomes unwanted. This is similar to finding by Kamal (2013) in a study done among urban women in Bangladesh who found that; up to $15.6 \%$ of the most recent pregnancy were unplanned and therefore unwanted due to domestic violence (physical/sexual) the violence that involved kicking, pushing, pulling hair, twisting arm among others.

The researcher found that abused urban married women in Bangladesh were less able to control their reproduction and $16 \%$ of them terminated pregnancy in their marital life.

Lack of discussion of family planning with husband was a determinant of UP among women in this study. This is consistent with the finding by Nguyen and Tuan (2015) in a study carried out in the Post Conflict setting of South Sudan, they found a lack of discussion of family planning to be associated with an unplanned pregnancy. Despite the obtainability of family planning stocks in health facilities, several rural and urban women did not want their husbands to know whether they are using contraceptives or not. This is because men of Renk county prefer and feels proud to have a large family. Women end up collecting contraceptives from far places which may be inconsistent hence UP.

Conceiving while still breastfeeding young babies was reported in this study. A participant expressed fear of the threat of malnutrition to the young breastfeeding baby if she gets pregnant. This is in line with the concepts of perceived severity explained in the Health Belief Model (Boskey, 2019). The participants perceived that unplanned pregnancy is an unhealthy practice that is associated with negative maternal and child health outcomes. For this case, a participant reported that 'carrying pregnancy while breast-feeding young babies would have a negative impact of malnutrition on the baby'.

Recurrent delivery of single-sex babies determines unplanned/unwanted pregnancy. A participant reported men in Awach community want specific gender of "baby boy" and they feel bad when a 
woman gets pregnant with baby girls many times. This is not documented anywhere in the literature review. However, this explains the unique culture of the Luo men which considers baby boys more important in family succession and inheritance, but girls get married away.

Recurrent obstetrical complications like sickle cell, epilepsy, abortion determined unplanned pregnancy in the study. Participants specifically reported that recurrent delivery of sickle celled babies inculcated fear in her because of the associated burdens like frequent hospitalization during a crisis. This means that any conception that happens to her turns to be unplanned/unwanted. This is congruent to the finding in the literature, which revealed complications in the past pregnancy, and premature baby as factors that determined unplanned pregnancy among women (Mariza et al., (2016). On the other hand, those who experienced pre-term birth or low weight of the baby at birth and complications by mother were more likely to respond negatively that they had an unplanned pregnancy.

Living far away from their husband was reported as a cause of unplanned pregnancy by women attending ANC. Participants reported that women whose husbands have gone far away to work for ARMISSION in Somalia, LDU training, or other jobs; lost faith and got involved in extramarital affairs with other men resulting in UP. This is parallel to finding by (Sebestian et al., 2014, Eleni et al., 2018, Mariza et al., 2016, Lawrence et al., 2013) who also found women staying far away from their spouses to have been 4-fold at risk to conceive without planning contrary to those living together with husbands.

\section{Community determinants of unplanned pregnancy}

Rape is another determinant of UP found in this study. The participant reported rape in marriage or rape by other men as a cause of unplanned pregnancy. Women who are raped may feel shy to seek emergency contraceptives or report the perpetrator, hence unplanned pregnancy. This relates to the finding by Yitayal and Azeb (2019) who found rape as a determinant of unplanned pregnancy among women in Addis Zemen hospital, Ethiopia.

Peer pressure determined UP in the current study. A participant reported pressure among peers; falsely encouraged girls to get in love with a wealthy man because he has a car or money. This is in line with Nguyen and Tuan, (2015) who found peer pressure among adolescents as a strong determinant of UP. In their study adolescent who had sexually active friends were 24 times at risk of UP compared to those without sexually active friends.

Denial of pregnancy by men was reported in the present study. Participants reported that when men deny pregnancy they are faced with challenges. Doctors and midwives demands for their husband to escort them for ANC and worst of all during labor. This makes them have felt that the pregnancy is not planned/unwanted. More so, participants ( $\mathrm{p} 3$ and $\mathrm{p} 6$ ) reported that men may only have sex with women to fulfill their sexual needs and goes away leaving them with burdens of responsibility like paying school fees; leaving a woman with ideas of removing the fetus. This finding is unique to this study area and not documented or related anywhere in the literature. This could be due to the unique culture of the Luo men related to their cultural practices like paying huge dowry or charges associated with impregnating a woman/girl before marriage. A man denies responsibility for impregnating a woman because of fear or inability to fulfill such payments.

\section{Health facility determinants of un- planned pregnancy}

Contraceptive failure was a determining factor of UP in this study. A participant testified to have been injected with Injecta plan (Depo provera) while menstruating but later she realized being pregnant after two months. This could mean that clients who attend family planning in this facility were not well assessed for pregnancy before injection or the methods could have expired. This is congruent with a study done in the United States where family planning method failure rates were high. They found a great number of failures among condom and withdrawal users and were low among those who used IUD and Implants (Aparna et al., 2017).

Lack of sensitization/guidance on family planning by health workers was found as a cause of unplanned pregnancy in this study. This means that lack of awareness of family planning is still a predictor of unplanned pregnancy in Awach H/C IV. This is consistent with Faiza et al., (2016) who reported unawareness of contraceptive methods as a determinant of UP in a study done among pregnant women attending ANC in Gelemso General Hospital, Eastern Ethiopia. 


\section{Conclusion}

This study has contributed substantially in revealing determinants of an unplanned pregnancy. In Awach Health Centre IV, the determinants of unplanned pregnancy are sexual desires, prostitution, school-going status, income level, number of sexual partners, amenorrhoea, marital status, contraceptives usage, religion, domestic violence, family planning discussion with husband. Others are recurrent obstetrical complications, distance from husband, rape, peer pressure, type of settlement, contraceptive failure, lack of sensitization, and age. However, this study found Conceiving while still breastfeeding young babies, recurrent delivery of single-sex baby and denial of pregnancy by men as determinants of unplanned pregnancy which is not found anywhere in the literature review.

\section{Nursing implications}

The following are suggestions for nurses:-

- Nurses should normalize contraceptive and preconceptual care to improve reproductive health.

- Coordination of adoptions will help to prevent associated risks of unplanned pregnancy, for example, abortion.

- Management and follow-up of unintended pregnancy is another suggestion that can be implemented by nurses.

- Secondary preventive services such as prenatal care and abortion care should be improved by nurses.

- This finding will provide a body of knowledge that will be beneficial for further research aimed at preventing unplanned pregnancy.

\section{Recommendations}

- There is a need for a multi-level approach to address determinants of unplanned pregnancy ranging from individuals, families, communities, and health facilities approach.

- There is a need to repackage health education messages during integrated outreaches to tackle knowledge gaps on sexual and reproductive health services and address violence against women.

- Improvement in the economic status of women, and implementing programs that encourage education of women/girl child could reduce unplanned pregnancy.

\section{Areas of future research}

There is a need to explore the Lived experiences of unplanned pregnancy among women attending antenatal care services in Awach Health Centre IV

\section{Acknowledgement}

The success of this research report is a result of tireless assistance from different people, may the Almighty God grant them abundant blessings.

I would like to express my special gratitude to the National Council of Higher Education (NCHE) for emphasizing research as the core of this course under the nursing department, MUST.

Special appreciation goes to Mrs. Catherine Atuhaire who taught us research methods, above all for the tremendous duty she executed in coordinating research as a course unit.

\section{List of abbreviations and}

ANC

$\mathrm{H} / \mathrm{C}$

HBM

HSD

MOH

SES

SSA

UDHS

Survey

UP

USA

WHO

\section{Operational definition of terms}

Grappling: Facing something, for example, unplanned pregnancy.

Determinant: Is defined as; an element that identifies or determines the nature of something or that fixes an outcome.

Unplanned pregnancy: Pregnancy that occurs when no children or no more children is desired at conception time, or pregnancy that is unwanted/unintended.

Outrageous: Out of hand, shocking, shameful.

Pre conceptual planning: Planning before getting pregnant.

\section{References:}

1) ADELAJA, L. M. (2015). Prevalence and determinants of unintended pregnancy among women in South Western Nigeria. Ghana medical Journal, 49, 187-194. https://doi.org/10.4314/gmj.v49i3.10

2) APARNA, S., BARBARA, V., KATHRYN, K., AKKINRINOLA, B., LAWRENCE, F., SUSHEELA, S. \& JAMES, T. (2017). Contraceptive failure in the United 
States:Estimates from the 2006- 2010 National Survey of the Family Growth. 49, 7-16. https://doi.org/ 10.1363/psrh.12017

3) AWACH HEALTH CENTRE IV, A. R. FY2018/2019. Annual Report.

4) ELBARDAN, H., OTHMAN,R.K. (2017). An Interpretive aapproach for data collection and analysis. Available: https://www.link.springer.com https://d oi.org/10.1007/978-3-319-54990-3_5

5) BOSKEY, E. (2019). Health Belief Model [Online]. California: verywellmind.com. Available: htt ps://www.verywellmind.com [Accessed 14 January 2019 2019].

6) BUKENYA, J. N., WANYENZE, R. K., BARRETT, G., HALL, J., MAKUMBI, F. \& GUWATUDDE, D. (2019). Contraceptive use, prevalence and predictors of pregnancy planning among female sex workers in Uganda: a cross sectional study. BMC pregnancy and childbirth, 19, 121. https://doi.org/10.1186/s1 2884-019-2260-4

7) EDWARD, K. A., EUGENE, B., FRANCIS, S., LENUS, B., FRANCIS, A., ABDUL, A. S. \& BIGHT, O. A. (2019). Prevalence and determinants of unintended pregnancy in Sub-Saharan Africa: A multi- country analysis of demographic and health surveys. plos.org, 14. https://doi.org/10.1371/journal.pone.0220970

8) ELENI, A., ALEMTSHAY, M., TESFAYE, S. \& ABEJE, G. (2018). Level of unintended pregnancy among reproductive age women in Bahir Dar city adminstration, Northwest Ethiopia. BMC research 11;2018. h ttps://doi.org/10.1186/s13104-018-4016-z

9) EMIRE, Y., SEMRA, A. \& NICOLE, P. (2012). Planned and unplanned pregnancy: Effects on health practice and depression during pregnancy. Journal of Obstetrics and Gynaecology Research, 39, 180- 187. https://doi.org/10.1111/j.1447-0756.2 012.01958.x

10) FAIZA, M., ABDUBASIT, M. \& ABDELLA, A. (2016). Prevalence and determinants of unintended pregnancy among pregnant women attending ANC at Gelemso General Hospital Oromya Region , East Ethiopia, A facility based cross -sectional study. pubMed, 16. https://doi.org/10.1186/s1290 5-016-0335-1

11) HABIB, M. A., RAYNES-GREENOW, C., NAUSHEEN, S., SOOFI, S. B., SAJID, M., BHUTTA, Z. A. \& BLACK, K. I. (2017). Prevalence and determinants of unintended pregnancies amongst women attending antenatal clinics in Pakistan. BMC pregnancy and childbirth, 17, 156. https://doi.org/1 0.1186/s12884-017-1339-z
12) JENNY, N., HULTSTRAND, T., TYDÉN, M. \& JONSSON, M. M. (2019). Contraception use and unplanned pregnancies in a peri-urban area of eSwatini (Swaziland). Volume 20, Pages 1-6. https://doi. org/10.1016/j.srhc.2019.01.004

13) KAMAL, M. (2013). Domestic Violence, Unwanted Pregnancy and Pregnancy Termination among Urban Women of Bangladesh. Journal of Family \& Reproductive Health, 7, 11-12.

14) LAWRENCE, I., CHIMARAOKE, I. \& RHAOUNE, O. (2013). Prevalence and determinants of unintended pregnancy among women in Nairobi, Kenya. 13. https://doi.org/10.1186/1471-2393-13-69

15) MANN, S. (2018). Health Matters: Reproductive health and Pregnancy Planning [Online]. Available: https://www.healthmatters.blog.gov.uk [Accessed 26 June 2018 2018].

16) MARGRET, E., SHIRA, M. G., MIRRIAM, A., KATHARINE, A. M., GODFREY, M. \& SHANNON, K. (2015). Structural determinants of dual contraceptive use among female sex workers in Gulu, Northern Uganda. International journal og gynaecology and obstetrics, 131. https://doi.org/10.1016/j.ijgo.2 015.04.029

17) MARIZA, M. T.-F., MARCIA, L. B., ANNA, C. S. A. F., SUSAN, A., SILVANA GRANADO NOGUEIRA DA GAMA \& MARIA, D. C. L. (2016). Factors associated with unintended pregnancy in Brazil: cross- sectional results from Birth in Brazil National survey, 2011/2012. Biomed central, 13. https://doi.org/10. 1186/s12978-016-0227-8

18) MATERNITY ADMISSION REGISTER BOOK, F. (2019). Number of cases admitted with abortion from July to September 2019. Awach Health Centre IV.

19) MILI, D., CHANDER, S. \& LOKENDER, P. (2015). Level, Trend and Correllates of Mistimed and Unwanted pregnancies among Currently Pregnat Ever Married Women in India. 10. https://doi.org/10.13 71/journal.pone.0144400

20) NGUYEN, T. V. \& TUAN, C. P. (2015). Factors influencing unintended pregnancy and abortion among unmarried youth in Vietnam: A literature Review.

21) POLIT, D. F. \& BECK, C. T. (2012). Nursing Research: Generating and Asssesing Evidence for Nursing Practice. Philadelphia: Wolters Kluwer Health/Lippincott Williams \& Wilkins. 9 ed.

22) RAMESH, A., KUSOL, S. \& PRAMOTE, P. (2009). Correllates of unintended pregnancy among current pregnant married women in Nepal [Online]. 
Available: https://biomedinthealthhuman.biomed central.com/articles/10.1186/1472-698X-9-17.ris 9]. https://doi.org/10.1186/1472-698X-9-17

23) REZA, O.-S., MOSTAFA, A. R., MAHDI, S., ESMEIL, K. M. \& AMIR, A.-H. (2018). Socioeconomic inequality of unintended pregnancy in the Iranian population: a decomposition approach. 18;2018. $\mathrm{h}$ ttps://doi.org/10.1186/s12889-018-5515-5

24) RUBINA, H. (2013). Unintended Pregnancy and Abortion in Uganda. Guttmacher Institute.

25) SEBESTIAN, E., FRANK, B., BARBRA, A. Y. \& KOFI, A.-A. (2014). Determinants of unintended pregnancy in Rural Ghana. 14. https://doi.org/10.1 186/1471-2393-14-261

26) SINGH, S., SEDGH, G. \& RUBINA, H. (2010). Unintended Pregnancy Worldwide Levels, Trends, and Outcomes. Wiley Online Library, 41. https://do i.org/10.1111/j.1728-4465.2010.00250.x

27) UDHS (2011). Uganda Demographic and Health Survey, . Kampala.

28) VICTORIA, I., KIRSTY, B., TAMSIM, K. N. P., STANZI, L. R., JAMES, A. M., ALLISON, Z., GREG, P., ELAINE, J. A. \& LONDON, M. (2018). Prevalence and determinants of unplanned pregnancy in HIVpositive and HIV- negative pregnant women in Cape town, South Africa: a cross-sectional study. pubMed, 8(4);2018. https://doi.org/10.1136/bmjop en-2017-019979

29) YIBELTAL, T., BEZUHAN, A. \& CHARLES, T. (2014). Prevalence and determinants of unintended childbirth in Ethiopia. pubMed, 14;2014. https://doi.org/10.1186/1471-2393-14-326

30) YITAYAL, A. G. \& AZEB, E. Y. (2019). Determinants and determinant factors of unintended pregnancy among pregnant women attending antenatal care clinics of Addis Zemen hospital. Hinari Research for Life, 14(1);2019. https://doi.org/10.13 71/journal.pone.0210206 